\title{
Towards Ways to Promote Interaction in Digital Learning Spaces
}

\author{
Hanna M. Olsson \\ Mid Sweden University, Östersund, Sweden \\ hanna.olsson@miun.se
}

\begin{abstract}
Social learning is dependent on social interactions. I am exploring ways to promote interaction in Digital Learning Spaces. As theoretical framework I use the types of interaction between learner, instructor and content. That learners feel isolated and lonely in DLSs is a problem which comes at high cost for social learning. My aim is to promote social interaction by offering the edentity: a system for making participants visible to each other by creation of a digital student identity.
\end{abstract}

Keywords: Edentity, social learning, presence, transparency, self-presentation.

\section{Introduction}

I am exploring ways to promote interaction in Digital Learning Spaces (DLSs). This involves testing and offering designs to make interaction more likely to occur. It seems fair to claim that in order to interact we need to know that the possibility to interact exists. A related aim is to make human resources available within DLSs. It is possible to do great things alone, but who would disagree that the result would be even greater with suitable support and contributions of others. This is in line with the ideas of Vygotsky [1] which is at base for how we picture learning today: as a social activity where a learner can reach the farthest with support of another person/other persons. Lave and Wenger [2] describe in their social theory of learning how participating in a community is at base for learning. Hence, the existence of a community should be fundamental in DLSs, why learners should first and foremost be visible to each other. Hence, the main questions of my PhD-work are:

- What is needed to promote interaction in DLSs?

- To what extent could explicitly expressed participant identities contribute to learners' motivation, experience and learning in DLSs?

To attend to those questions I will take on a design approach, and design and test the edentity. The edentity is my proposition of a way of making participants visual, and hence available for interaction [3, 4]. I have an overall interpretive approach towards my work. I study adult learning in diverse contexts, such as workplace and higher education, with the unifying aspect of taking place within a DLS. With DLS, I mean an interactive information space (conceptual space in $2 \mathrm{D}$ or $3 \mathrm{D}$ ) used for learning-related 
activities, contained in a digital environment which can consist of diverse modes (i.e. text, still image, moving image, and sound).

\section{Theoretical Foundations and Related Research}

Moore [5] describes three types of interaction which takes place in between the three agents of learner, instructor and content. I use these types of interaction as the framework in my work. A theoretical baseline for my work is that learning is a social activity, in accordance with the theories of for example Vygotsky [1] and Lave and Wenger [2]. For social learning to at all exist, interaction is required. However, it has been argued that interaction only is not enough for learning to be successful [6]. However, when learning in DLSs it is crucial that learners perceive each other as real people, i.e. that there is social presence [7]. The DLS also need to allow transparency, so that participants can see that others are there and available for interaction [8]. Hence, designing DLSs for presence and transparency is at the base for enabling social learning in DLSs. In an environment with high presence and transparency, identity expressions are needed. I refer to identity in the terms of a subjective selfrepresentation. I derive this way of considering identity from social sciences (see for example Hogg [9] for a theoretical discussion). Digital identity is in literature mostly treated in regard of identification in the terms of digital identity management. This way of considering digital identity is widely separated from my work on digital identity. However, some contributions can be seen from the digital identity management track, such as that digital identities must be student controlled and student owned in order to feel safe to provide personal information [10]. E-portfolios have been described as a way to construct one's digital identity (in combination with Personal Learning Environment and Social Network) [11]. I have argued that e-portfolios might be part of one's digital identity, but that it is far from enough [3]. I base this argument on the traditional use of portfolios as a way to showcase abilities, and our abilities are only a small part of our identities. For a discussion what else makes our identities I direct readers to my and PhD Thomas Persson Slumpi's OST12 conference contribution [4].

\section{Results}

In figure 1, I have illustrated my work process by questions, activities and manuscripts, and how they relate to each other. The first activity that I performed was an explorative field study at a military defense academy. Supported by an instructor and two DLSs, a self-paced multimedia production and a battle simulator, soldiers were preparing for an assignment in Afghanistan. I was exploring strengths and weaknesses of DLSs, and in the studied situation the social dimension stood out as a clear asset. In the resulting manuscript 1 (m1) [12] I mapped feedback onto Moore's [5] lanes of interactions. Even though a social dimension was highly present, I judged feedback in the studied situation as incomplete. For example, feedback from the participants to the system developers was non-existent. Based on that insight I have 
another manuscript waiting to be written on a missing type of interaction agent, the system designer (m2).

At present, I am performing a case study with a mixed approach of user testing and interviews, in order to explore strengths and weaknesses of DLSs on a learner-content level. It is expected to result in $\mathrm{m} 3$ on interaction in multimedia manual.

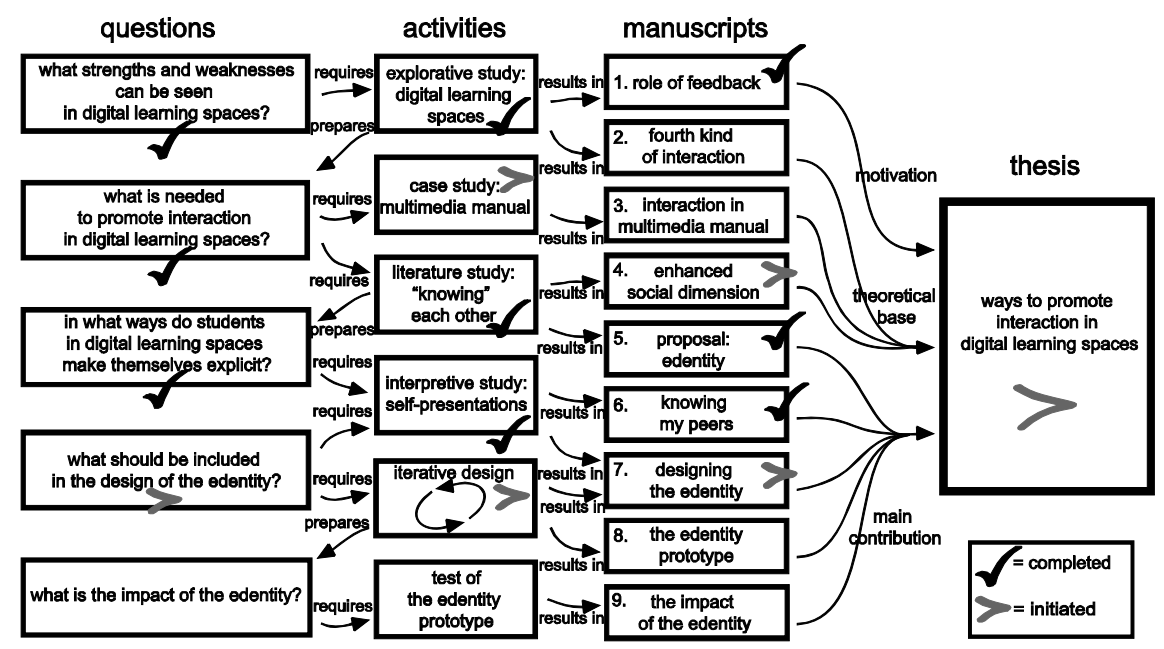

Fig. 1. Illustration of my work process

The results of the first study led me to the next question, namely: what is needed to promote interaction in DLSs? Hence, I performed a literature review on knowing each other in DLSs, resulting in the first proposal of the edentity: a system for making participants visible to each other by creation of a digital student identity [3] (m5). The idea of the edentity system comprises profile data, pre-knowledge, and meta-information about actions and progress, in a private, dynamic system that should be able to be migrated between all DLSs in which the student participates. Hence, it allows identity expression to be developed over time. I am also writing a more general manuscript on what is needed to create feelings of knowing each other in DLSs (m4).

This latter question was also attended to by an interpretive study where my colleague Thomas Person Slumpi and I analyzed existing self-presentations. A result of this study is m6, about knowing my peers [4]. This manuscript also addresses the question of what should be included in the design of the edentity. However, the design question is only partly answered by the study on self-presentations. The ongoing activity of iterative design of the edentity will give additional input to this question, presented in a next manuscript $(\mathrm{m} 7)$ on designing the edentity. The iterative design activity will be ongoing during this, and the next coming year. Ultimately, it is expected to result in a testable prototype (m8), and tested in a sharp learning situation (m9), planned to be a university course given in the LMS Moodle and the prototype will then be a plug-in to Moodle. However, the aim is to make the edentity a platform independent stand alone system that will be pluggable to any DLS. 


\section{Concluding Remarks}

What has intrigued me the most is how humans interaction in and through DLSs can be facilitated. Much research concerning DLSs is carried out, and a variety of perspectives and approaches contribute to the area. However, self-presentations in learning situations from an information systems perspective have not gotten much attention. Many agree that learning is a social activity, but only making sure that interaction takes place is not enough to make a learning situation prosperous. However, systems which obstruct social interaction just by being opaque and impersonal can be devastating to any learning situation. It is my aim to contribute to the social dimension of DLSs, ultimately by offering the edentity as a possible way for participants to become visible to each other.

\section{References}

1. Vygotsky, L.S., Cole, M.: Mind in society: the development of higher psychological processes. Harvard University Press, Cambridge (1978)

2. Lave, J., Wenger, E.: Situated learning: legitimate peripheral participation. Cambridge University Press, Cambridge (1991)

3. Olsson, H.: Proposing Learner E-dentity to social presence in digital spaces for learning. In: Asproth, V. (ed.) Challenges for the Future in an ICT Context, pp. 177-186. Mid Sweden University, Östersund (2011)

4. Olsson, H., Slumpi, T.P.: Knowing my peers - Edentity: to invite peer interaction and social learning. In: OST 2012, Tallinn (2012) (accepted)

5. Moore, M.G.: Three types of interaction. In: Harry, K., John, M., Keegan, D. (eds.) Distance Education: New Perspectives, pp. 19-24. Routledge, London (1993)

6. Garrison, D.R., Cleveland-Innes, M.: Facilitating Cognitive Presence in Online Learning: Interaction Is Not Enough. Am. J. of Distance Education 19(3), 133-148 (2005)

7. Gunawardena, C.N., Zittle, F.J.: Social presence as a predictor of satisfaction within a computer-mediated conferencing environment. Am. J. of Distance Education 11(3), 8-26 (1997)

8. Dalsgaard, C., Paulsen, M.F.: Transparency in Cooperative Online Education. The International Review of Research in Open and Distance Learning 10(3) (2009)

9. Hogg, M.A., Terry, D.J., White, K.M.: A Tale of Two Theories: A Critical Comparison of Identity Theory with Social Identity Theory. Social Psychology Quarterly 58(4), 255-269 (1995)

10. Satchell, C., Shanks, G., Howard, S., Murphy, J.: Identity crisis: user perspectives on multiplicity and control in federated identity management. Behaviour \& Information Technology 30(1), 51-62 (2009)

11. Bauer, R.: Construction of One's Identity: A Student's View on the Potential of EPortfolios. Studienverlag GmbH, Wien (2009)

12. Olsson, H.M., Öberg, L.-M.: Role of feedback in uniform learning situation. In: Proceedings of the 29th ACM International Conference on Design of Communication, pp. 279-284. ACM, New York (2011) 